\title{
Review \\ Nasal Delivery of Acute Medications for Migraine: The Upper Versus Lower Nasal Space
}

\author{
Vincent Martin ${ }^{1}$, John Hoekman ${ }^{2}$, Sheena K. Aurora ${ }^{3}$ and Stephen B. Shrewsbury ${ }^{4, *}$ \\ 1 University of Cincinnati Headache and Facial Pain Center, Cincinnati, OH 45219, USA; \\ martinvt@ucmail.uc.edu \\ 2 Research \& Development, Impel NeuroPharma, Seattle, WA 98119, USA; jhoekman@impelnp.com \\ 3 Medical Affairs, Impel NeuroPharma, Seattle, WA 98119, USA; saurora@impelnp.com \\ 4 Clinical Development, Impel NeuroPharma, Seattle, WA 98119, USA \\ * Correspondence: sshrewsbury@impelnp.com
}

Citation: Martin, V.; Hoekman, J.; Aurora, S.K.; Shrewsbury, S.B. Nasal Delivery of Acute Medications for Migraine: The Upper Versus Lower Nasal Space. J. Clin. Med. 2021, 10, 2468. https://doi.org/10.3390/ jcm10112468

Academic Editor: Antonio Russo

Received: 28 April 2021

Accepted: 27 May 2021

Published: 2 June 2021

Publisher's Note: MDPI stays neutral with regard to jurisdictional claims in published maps and institutional affiliations.

Copyright: (c) 2021 by the authors. Licensee MDPI, Basel, Switzerland. This article is an open access article distributed under the terms and conditions of the Creative Commons Attribution (CC BY) license (https:// creativecommons.org/licenses/by/ $4.0 /)$.

\begin{abstract}
The acute treatment of migraine requires effective drugs that are well tolerated and provide rapid and consistent pain relief. Oral tablets are the most commonly used acute treatment for migraine; however, their effectiveness is limited by the rate of gastrointestinal (GI) tract absorption and first-pass hepatic metabolism, and they may not be ideal for patients experiencing GI motility issues. Nasal delivery is an attractive alternative route as it may circumvent GI tract absorption, avoid first-pass metabolism in the liver, and potentially reduce the frequency of GI adverse events. The large surface area and high vascularity within the nose may permit rapid absorption of therapeutics into the systemic circulation, allowing for rapid onset of action. However, the site of drug deposition (upper versus lower nasal cavity) may influence drug pharmacokinetics. Most approved nasal migraine therapies target the lower nasal space where the epithelium is less permeable, and they may be quickly cleared away due to increased ciliary function or dripping from the nose or swallowing, resulting in variable absorption and limited bioavailability. Together with its abundant vascularization, relative mucosal thickness stability, and low clearance rates, the upper nasal space harnesses the benefits of nasal delivery to potentially maximize drug efficacy.
\end{abstract}

Keywords: migraine; headache; acute treatment; therapy; nasal delivery; drug delivery; bioavailability; upper nasal space; olfactory region

\section{Introduction}

Migraine is a debilitating condition, representing the second leading cause of disability globally [1-4]. In a recent epidemiological study in the United States (US), 19.2\% of individuals have self-reported a migraine, with $15.8 \%$ reporting at least one monthly headache day over a 3-month period. Of the 18,353 respondents who met criteria for migraine, migraine disproportionately affected women versus men. Of the 15,133 (women; $n=11,049$, men; $n=4084$ ) reporting at least one migraine headache day per month, the ratio of women to men with migraine was 3:1 [5]. Overall, 18\% of American women and $6 \%$ of men experience migraine headaches [6].

It is estimated that more than $90 \%$ of individuals use medication for the acute treatment of their migraine headaches $[7,8]$. However, approximately $36 \%$ of those who use medication for their headaches discontinue treatment, and lack of treatment efficacy ranks among the top reasons for suspending treatment [8,9]. While numerous administration routes for acute therapy for migraine exist, oral tablets are the most commonly prescribed for patients, totaling over $90 \%$ of therapies prescribed [5]. Oral drugs offer unique advantages, including portability and ease of administration [10]. However, bioavailability, or the rate and extent to which a drug reaches the systemic circulation, becomes a challenge with oral administration because oral drugs must first pass through the stomach and into the small intestine of the gastrointestinal (GI) system before they can be absorbed [11,12]. 
Bioavailability is subject to variations in intestinal absorption, and in addition, even wellabsorbed drugs may then undergo high rates of hepatic first-pass metabolism, which may make them pharmacologically inactive [10-13]. Additionally, disparities in gut motility and metabolism among individuals, and even within an individual on different occasions, may affect bioavailability $[12,14]$. A drug that is rapidly absorbed in the GI system of a healthy individual may stall in the stomach of some migraine patients. Most pharmacokinetic studies are conducted in healthy volunteers, with the exception of those identified by the Food and Drug Administration (FDA) that should be conducted in a defined patient population $[12,15]$. While it would be ideal to conduct pharmacokinetic studies of oral migraine drugs in migraine patients during an attack, it is not practical; therefore, other methods to understand the impact of gut motility in the patient population must be employed in order to effectively assess drug absorption and bioavailability. Finally, oral medications may not be ideal for migraine patients experiencing gastroparesis, as delayed absorption may allow migraine symptoms to worsen. Migraine commonly accompanied by nausea may lead to reluctance to take oral treatment, and vomiting may lead to ingested drugs being lost in vomitus and uncertainty about whether to re-dose. [11,16-19]

Alternative routes of administration for the acute treatment of migraine include injection (subcutaneous (SC), intramuscular (IM), or intravenous (IV)), transdermal, and inhalation (nasal and pulmonary) $[17,19,20]$. Injection and inhalation (both pulmonary and nasal) offer rapid relief ( $<15 \mathrm{~min}$ ) from migraine; although IV injection may be faster and more consistent than SC or IM injection, it requires staff to administer $[17,19,21]$. While IV injection completely bypasses gastric stasis issues and hepatic first-pass metabolism, some drugs may worsen nausea and vomiting or other concentration-dependent adverse events (AEs) due to a rapid increase in plasma and brain concentrations. Injections may also represent a problem for those patients who are averse to needles [19]. Advantages of inhaled delivery include at-home administration, non-invasiveness, and easy self-administration as well as avoidance of drug degradation in the GI tract and first-pass metabolism (similar to injection), which allows for enhanced bioavailability and reduction of systemic side effects without the use of a needle [22,23].

Migraine and disorders of the nose can be comorbid conditions, which suggests a possible underlying pathophysiological relationship [24]. Rhinitis is a comorbidity of migraine, and epidemiological studies have shown that a relationship between rhinitis and migraine exists $[25,26]$. A 2008 questionnaire study demonstrated that the frequency of migraine attacks is significantly increased in patients with rhinitis and that rhinitis is associated with increased headache disability [26]. Another study demonstrated that migraine was significantly more prevalent in patients with rhinitis $(34 \% ; p<0.001)$ and that the odds of experiencing a migraine attack were 14.3 times higher in patients with rhinitis [25]. Additionally, unilateral cranial autonomic symptoms (UASs), which include nasal congestion and rhinorrhea, can occur during a migraine attack. A 2006 study revealed that migraine patients with UASs experienced longer migraine duration, increased head pain severity, and more frequent allodynia and photophobia compared to migraine patients without UASs [27]. Olfactory triggers are common in those with migraine, occurring in $90 \%$ of migraine patients in a 2016 study. In those patients who experienced odor-triggered migraine attacks, osmophobia was reported by $95 \%$ of patients. Additionally, reduced olfactory acuity was reported by patients who experienced osmophobia and odor-triggered headaches [28]. Such evidence underpins a connection between the nose and migraine, and thus a nasal treatment may make more logical sense than previously appreciated. 
Nasal delivery has promised to be an effective alternative route of administration for over 25 years, yet despite many effective migraine drugs being formulated for nasal administration, they have failed to generate the consistent or convincing efficacy data for all patients with all migraine attacks and most have not been commercially successful $[23,29,30]$. This review will discuss the shortcomings of approved nasally delivered therapies and the current attempts to overcome the issues associated with traditional nasal delivery of acute medications for migraine. The nose is a complex organ and the need to deliver efficacious medication to the appropriate anatomical region of the nose may have been underestimated.

\section{Nasal Delivery: All Parts of the Nose Are Not the Same}

The upper respiratory tract includes the nasal cavities and passages, pharynx, tonsils, and larynx, while the trachea and lungs make up the lower respiratory tract [31,32]. The upper respiratory tract serves to filter, humidify, and warm the air that is delivered to the lower respiratory tract [32]. The nose can be divided into an upper and a lower nasal space (Figure 1) [33,34]. The lower nasal space is located more anteriorly, just posterior to the nasal openings, and includes structures such as the vestibule and the nasal turbinates [33]. The upper nasal space lies just beyond the lower nasal space and contains the upper portion of the superior turbinate, the inferior surface of the ethmoid bone, and the olfactory region [33-35]. The upper and lower nasal spaces differ in epithelium type, ciliary function, vascular supply, but share innervation by the trigeminal nerve [11,36,37]. The trigeminal nerve innervates both the lower and upper nasal spaces and has been considered a common denominator in headache pathophysiology as it also supplies sensory innervation to other parts of the head and face [36-38]. It has been termed a "central hub" in the trigeminovascular pathway transmission because it ultimately signals to the cortex through hypothalamic activation [38]. The trigeminal nerve receives and processes nociceptive and sensory signals and innervates intracranial vasculature. Its sensory receptors cover meningeal perivascular nerves of pial and dural blood vessels $[38,39]$. Thalamic trigeminovascular neurons contribute to migraine pain and mediate many migraine-associated symptoms, such as phonophobia, photophobia, allodynia, and osmophobia [39-41]. 

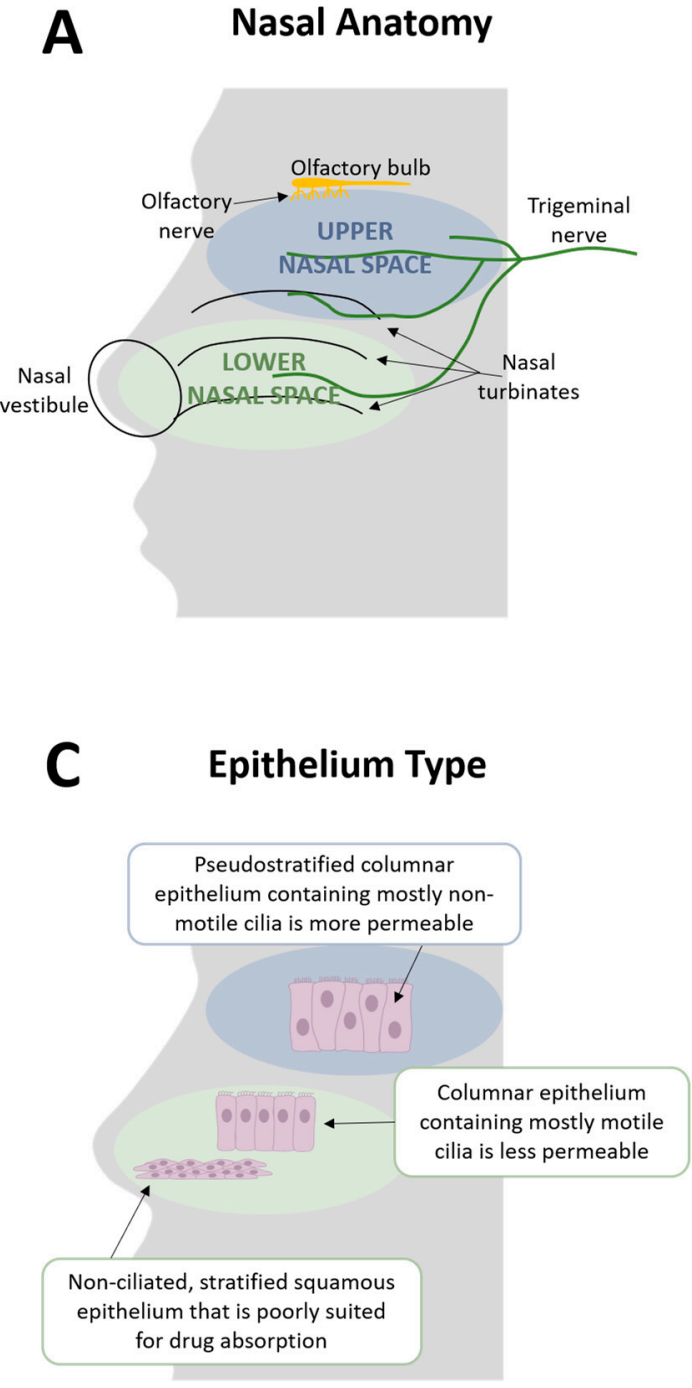

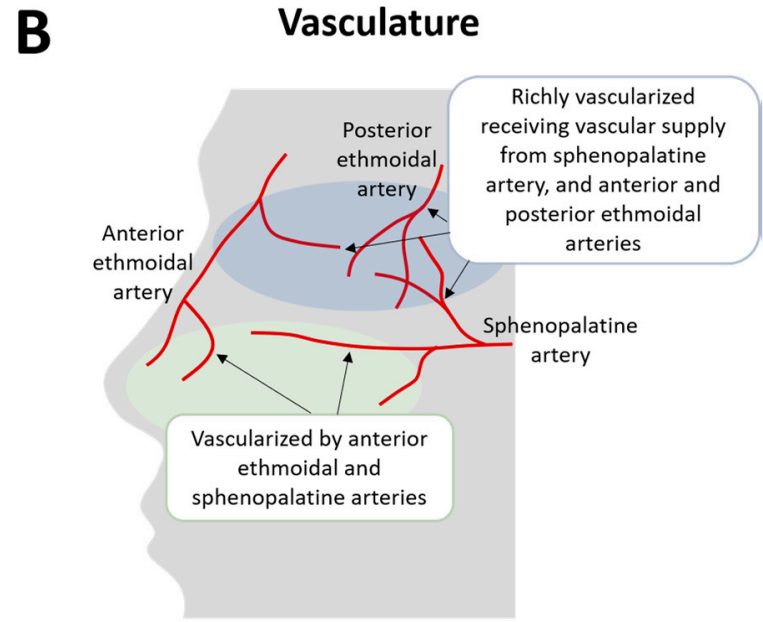

D Clearance

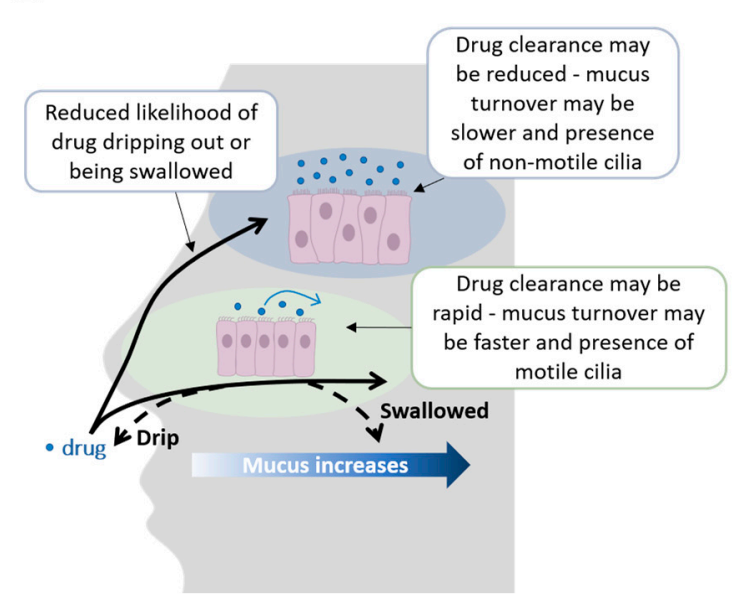

Figure 1. Anatomy, vasculature, epithelia, and clearance in the upper versus lower nasal space. (A) The nose is divided into an upper and a lower nasal space [33,34]. The lower nasal space is located just posterior to the nasal openings and includes the vestibule and the nasal turbinates [33]. It is innervated by the trigeminal nerve [11,35]. The upper nasal space contains the upper portion of the superior turbinate, the inferior surface of the ethmoid bone, and the olfactory region [33,35]. It is innervated by both the olfactory and trigeminal nerves [11]. (B) The vascular supply in the lower nasal space derives from branches of the ophthalmic and maxillary arteries, specifically the anterior ethmoidal artery and the sphenopalatine artery $[11,42]$. The upper nasal space is abundantly vascularized, receiving vascular supply from the sphenopalatine artery and the anterior and posterior ethmoidal arteries [43]. (C) The lower nasal space contains mostly non-ciliated, stratified squamous epithelium in the vestibular region, which is poorly suited for drug absorption, and ciliated columnar cells predominate in its respiratory region [35,37]. Pseudostratified columnar epithelium containing mostly non-motile cilia is present in the olfactory epithelium of the upper nasal space [37,44]. The olfactory epithelium is more permeable than the respiratory epithelium and may allow for better drug absorption [23,45]. (D) Within the nasal cavity, there is the presence of mucus which a drug must pass through, and mucus increases in an anterior to posterior manner [46-48]. Mucus in the olfactory region is produced and secreted by Bowman's glands, and from both seromucous glands and goblet cells in the respiratory mucosa [37]. A rodent study demonstrated that mucus in the olfactory mucosa moves slowly, with a turnover time of several days, while mucus in the respiratory region turns over rapidly, with an estimated turnover time of approximately $10 \mathrm{~min}[46,49]$. Potentially slower mucus turnover, and decreased presence of motile cilia in the upper nasal space, may result in reduced mucociliary clearance from the upper nasal region [37,44]. Additionally, drug delivery to the upper nasal space may have a reduced likelihood of dripping out or being swallowed [23,34,37]. Compared to the lower nasal space, drug delivery to the upper nasal space may provide greater, more consistent drug absorption, and thus may reduce response variability and provide greater, rapid relief [34,50,51]. Note: Images are not drawn to scale. 


\subsection{Lower Nasal Space}

Within the lower nasal space lies the most anterior vestibular region immediately posterior to the nostril openings. This region contains nasal hairs that filter inhaled particles and non-ciliated, stratified squamous epithelium. It encompasses a relatively small total surface area of $0.6 \mathrm{~cm}^{2}$, which may be a possible reason for minimal drug absorption in this area $[11,33,35,37]$. The respiratory region lies just posterior to the vestibular region and has a large mucosal surface area of approximately $130 \mathrm{~cm}^{2}$, covering the lateral walls of the nasal cavity and the three projecting nasal turbinates (Figure 1) [35,52]. This region contains ciliated respiratory epithelium, with nearly $80 \%$ of the cells within the respiratory mucosa containing motile cilia $[11,37]$. Mucus production in this area comes from seromucous glands and goblet cells $[37,44]$ The presence of mucus increases in an anterior to posterior gradient [46-48]. It turns over rapidly, with an estimated turnover time of approximately $10 \mathrm{~min}$ as assessed in the rodent $[46,49]$. The respiratory region is vascularized by branches of the ophthalmic and maxillary arteries supplying the mucosal membranes of this region, and its neural innervation comes from the trigeminal nerve [11,35]. While its large surface area and high vascularity make the respiratory region within the lower nasal space a promising location for drug delivery, absorption across the respiratory mucosa of the vestibule, lower nasal space, and associated middle and lower turbinates may be variable. Underlying mucosal edema from allergic or infectious disease may lead to inconsistent response, or mucus trapping and then clearing the drug via mucociliary clearance may slow absorption $[34,35,37,44,53]$. Most nasal sprays have been developed to deliver to the lower nasal space [11,33]. However, limited and inconsistent systemic absorption has been reported with traditional nasal sprays, which were specifically developed to treat local nasal and upper airway diseases in which systemic absorption is neither required nor desired (e.g., when using corticosteroids or decongestants for allergic or viral rhinitis) [23,33]. Drugs delivered to the lower nasal space may be quickly swept away by mucociliary clearance or drained away due to gravity from the nasal cavity and driven toward the nasopharynx, where they are swallowed or expectorated, resulting in variable absorption $[23,34,37,44]$. While several nasal therapies for the treatment of migraine exist, traditional nasal spray devices deposit less than $5 \%$ of the active drug into the upper nasal space and have been developed to deliver to the lower nasal space, where their rapid clearance results in limited bioavailability and inconsistent clinical results [11,23,37].

\subsection{Upper Nasal Space}

Beyond the respiratory region in the superior aspect of the nasal cavity lies the upper nasal space, which contains the olfactory mucosa $[34,35]$. The olfactory region consists of a pseudostratified columnar epithelium covering the septum, the upper portion of the superior turbinate, the lateral surface of the posterosuperior portions of both nasal cavities, and the inferior surface of the ethmoid bone's cribriform plate $[35,43,54]$. Mucus is produced and secreted by Bowman's glands in this region, and moves slowly, with a turnover time of several days as assessed in the rodent $[37,44,46,49]$. The olfactory region is abundantly vascularized, receiving vascular supply from the sphenopalatine artery and anterior and posterior ethmoidal arteries [43]. Neural innervation to this area is supplied by both the olfactory and trigeminal nerves $[11,36,37]$. Unlike the respiratory mucosa in the lower nasal space where nearly all cells are covered with motile cilia, non-motile cilia are found in the olfactory mucosa in the upper nasal region [37]. However, gravitational forces and small islets of respiratory mucosa containing motile cilia in this region do contribute to mucociliary clearance $[37,44]$. The decreased presence of motile cilia in the upper nasal space may result in reduced mucociliary clearance in this cavity. Therefore, delivery of a therapeutic to this space may result in increased absorption, which otherwise would not have occurred if the drug were quickly cleared away [23,37,55-57]. Additionally, the olfactory epithelium is more permeable than the respiratory epithelium [45]. A rich network of blood and lymphatic vessels present in the underlying submucosa of the olfactory region may enhance drug absorption by draining substances, that are not absorbed into the 
bloodstream, into the lymphatic system for systemic absorption [22,44,50]. Compared to the lower nasal space, delivery of drugs to the upper nasal space has the potential to provide greater, more consistent drug absorption, and thus may reduce response variability and provide reliable relief in a non-invasive manner [23,34,50,51].

\subsection{Additional Factors That May Impact Nasal Drug Delivery}

Other factors that can influence the efficiency of nasal delivery besides the location of drug deposition within the nose include physiochemical properties of the active pharmaceutical ingredient (API; e.g., molecular size, lipophilicity/polarity/ionic charge, enzymatic degradation in the nose), as well as properties of its formulation (e.g., dry powder, liquid, concentration, $\mathrm{pH}$, osmolarity, viscosity) [58]. Just as device factors (e.g., spray pattern, plume geometry, dose volume, droplet size distribution, velocity) can influence where in the nose the drug is deposited, formulation strategies (e.g., enzyme inhibitors, permeation enhancers, particulate design) can also influence uptake across the nasal mucosa $[58,59]$.

\section{Overview of Nasal Products That Are in Development or Approved, Including Efficacy, Safety, and Bioavailability}

There are currently several nasal products that are approved for the acute treatment of migraine. While nasal powder formulations exist, the nasal drug market is currently dominated by liquid formulations [60]. They are summarized below and in Table 1. 
Table 1. Approved nasal products for the acute treatment of migraine.

\begin{tabular}{|c|c|c|c|c|c|c|}
\hline Product & $\begin{array}{l}\text { Initial US } \\
\text { Approval } \\
\text { Date }\end{array}$ & Key Product Details & Dosage & BAV & $\begin{array}{l}\text { Key Efficacy } \\
\text { Details }\end{array}$ & $\begin{array}{l}\text { Key Safety } \\
\text { Details }\end{array}$ \\
\hline $\begin{array}{c}\text { IMITREX }^{\circledR} \\
\text { (sumatriptan); } \\
\text { GlaxoSmithKline, } \\
\text { Research Triangle } \\
\text { Park, NC, USA } \\
{[29,60,61]}\end{array}$ & 1997 & $\begin{array}{ll}\text { - } & \text { Liquid formulation } \\
\text { delivered via traditional } \\
\text { nasal spray } \\
\text { - } \quad \text { Indicated for the acute } \\
\text { treatment of migraine } \\
\text { with or without aura }\end{array}$ & $\begin{array}{l}5,10, \text { or } \\
20 \mathrm{mg}\end{array}$ & $\begin{array}{l}17 \% \text { relative to } \\
\text { SC }\end{array}$ & $\begin{array}{ll}\text { - } & \text { Eight randomized, double-blind, } \\
\text { placebo-controlled trials }(5 \text { used } \\
\text { recommended dosing/ marketed } \\
\text { formulation) } \\
\text { - } \quad \text { Results reported for a single attack } \\
\text { - } \\
\text { Significantly greater percentage of patients } \\
\text { achieved headache relief at } 2 \mathrm{~h} \\
\text { post-treatment with } 10(p<0.05) \text { or } 20 \mathrm{mg} \\
(p<0.05) \text { IMITREX vs. placebo in } 4 / 5 \\
\text { studies }\end{array}$ & $\begin{array}{l}\text { Most commonly reported AEs in controlled } \\
\text { studies were burning sensation, } \\
\text { disorder/discomfort of nasal cavity/sinuses, } \\
\text { throat discomfort, nausea, vomiting, } \\
\text { bad/unusual taste, and dizziness/vertigo }\end{array}$ \\
\hline $\begin{array}{l}\text { MIGRANAL }^{\circledR} \\
\text { (dihydroergotamine } \\
\text { mesylate); } \\
\text { Bausch Health } \\
\text { Companies Inc. or its } \\
\text { affiliates, Bridgewater, } \\
\text { NJ, USA } \\
{[23,51,62,63]}\end{array}$ & 1997 & $\begin{array}{l}\text { - } \quad \begin{array}{l}\text { Liquid formulation } \\
\text { delivered to the lower } \\
\text { nasal space }\end{array} \\
\text { - } \quad \text { Indicated for the acute } \\
\text { treatment of migraine } \\
\text { with or without aura }\end{array}$ & $2 \mathrm{mg}$ & $32 \%$ relative to IV & $\begin{array}{l}\text { - Four randomized, double-blind, } \\
\text { placebo-controlled, single-attack studies } \\
\text { Significantly greater percentage of patients } \\
\text { achieved headache relief with } 2 \mathrm{mg} \\
\text { MIGRANAL vs. placebo at } 2 \mathrm{~h} \\
\text { post-treatment in } 1 / 4 \text { studies }(p<0.001) \text { and } \\
\text { at } 4 \mathrm{~h} \text { post-treatment in } 3 / 4 \text { studies }(p<0.01)\end{array}$ & 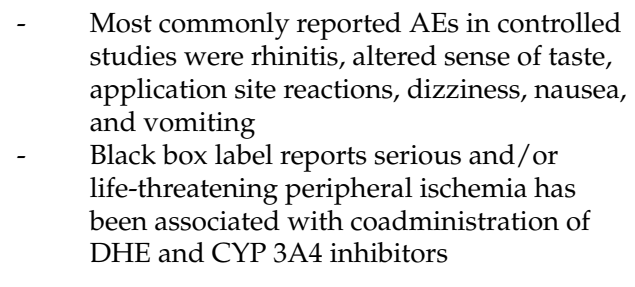 \\
\hline $\begin{array}{c}\text { ZOMIG }^{\circledR} \\
\text { (zolmitriptan); } \\
\text { Amneal } \\
\text { Pharmaceuticals, } \\
\text { Bridgewater, NJ, USA } \\
{[33,64-68]}\end{array}$ & 2003 & $\begin{array}{l}\text { Liquid formulation } \\
\text { delivered to the } \\
\text { nasopharynx and lower } \\
\text { nasal space } \\
\text { Indicated for the acute } \\
\text { treatment of migraine } \\
\text { with or without aura }\end{array}$ & 2.5 or $5 \mathrm{mg}$ & $\begin{array}{l}102 \% \text { relative to } \\
\text { oral }\end{array}$ & $\begin{array}{l}\text { - } \quad \begin{array}{l}\text { One multi-attack trial for adults } \\
\text { One single-attack trial for adolescents }(12-17\end{array} \\
\text { years) } \\
\text { Both randomized, double-blind, } \\
\text { placebo-controlled, dose-ranging trials } \\
\text { Significantly greater percentage of patients } \\
\text { achieved headache relief at } 2 \text { h with } 2.5 \text { or } 5 \\
\text { mg ZOMIG vs. placebo in adults }(p<0.001) \\
\text { and adolescents }(p<0.05) \\
\text { A randomized, double-blind, parallel-group, } \\
\text { multicenter study designed as a two-phase, } \\
\text { crossover trial assessed long-term } \\
\text { tolerability, efficacy, and consistency of } \\
\text { response of ZOMIG over } 1 \text { year }\end{array}$ & $\begin{array}{l}\text { - Most commonly reported AEs in controlled } \\
\text { studies were unusual taste, paresthesia, } \\
\text { dizziness, and hyperesthesia in adults and } \\
\text { unusual taste in adolescents } \\
\text { Long-term safety study revealed } 5 \mathrm{mg} \\
\text { ZOMIG was well tolerated over the course } \\
\text { of } 6 \text { months, with unusual taste and } \\
\text { paresthesia being the most frequently } \\
\text { occurring AEs }\end{array}$ \\
\hline
\end{tabular}


Table 1. Cont.

\begin{tabular}{|c|c|c|c|c|c|c|}
\hline Product & $\begin{array}{l}\text { Initial US } \\
\text { Approval } \\
\text { Date }\end{array}$ & Key Product Details & Dosage & BAV & $\begin{array}{l}\text { Key Efficacy } \\
\text { Details }\end{array}$ & $\begin{array}{l}\text { Key Safety } \\
\text { Details }\end{array}$ \\
\hline $\begin{array}{l}\text { ONZETRA }^{\circledR} \text { Xsail }^{\circledR} \\
\text { (sumatriptan); } \\
\text { Currax } \\
\text { Pharmaceuticals, } \\
\text { Morristown, NJ, USA } \\
\text { [69-73] }\end{array}$ & 2016 & 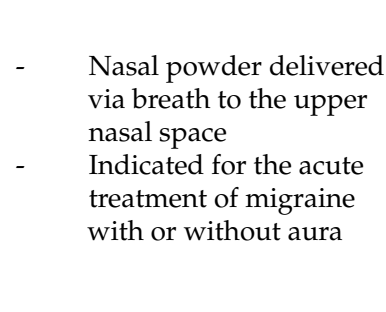 & $22 \mathrm{mg}$ & $\begin{array}{l}19 \% \text { relative to } \\
\text { SC }\end{array}$ & $\begin{array}{l}\text { - One multicenter, randomized, double-blind, } \\
\text { placebo-controlled, single-attack study } \\
\text { Significantly greater percentage of patients } \\
\text { achieved headache relief at } 2 \mathrm{~h} \text { with } 22 \mathrm{mg} \\
\text { ONZETRA Xsail vs. placebo }(p<0.05) \\
\text { Consistency of response was assessed in a } \\
\text { randomized, multicenter, double-dummy, } \\
\text { crossover, multi-attack, comparative efficacy } \\
\text { study }\end{array}$ & $\begin{array}{l}\text { Most commonly reported AEs in the } \\
\text { controlled study were abnormal taste, nasal } \\
\text { discomfort, rhinorrhea, and rhinitis }\end{array}$ \\
\hline $\begin{array}{l}\text { TOSYMRA } \\
\text { (sumatriptan); } \\
\text { Upsher-Smith } \\
\text { Laboratories, Maple } \\
\text { Grove, MN, USA } \\
\text { [74-78] }\end{array}$ & 2019 & 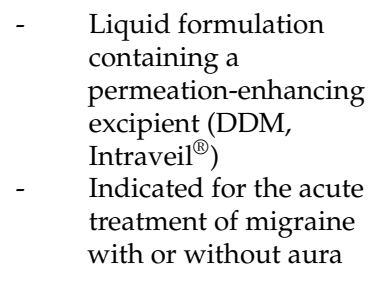 & $10 \mathrm{mg}$ & $\begin{array}{l}-87 \% \\
\text { relative to } \\
4 \mathrm{mg} \mathrm{SC} \\
58 \% \\
\text { relative to } \\
6 \mathrm{mg} \mathrm{SC}\end{array}$ & 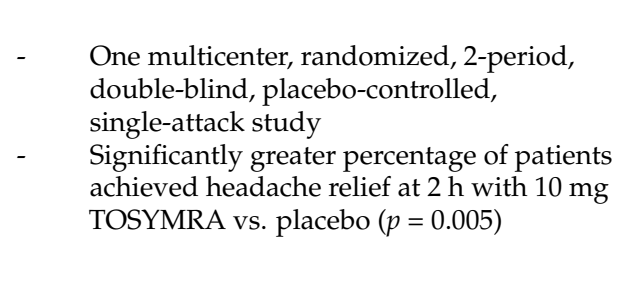 & $\begin{array}{l}\text { Most commonly reported AEs in controlled } \\
\text { studies were application site reactions and } \\
\text { dysgeusia } \\
\text { The most common AEs reported over } 6 \\
\text { months from the open-label study were } \\
\text { application site pain, dysgeusia, application } \\
\text { site reaction, upper respiratory infection, } \\
\text { nasopharyngitis, and sinusitis }\end{array}$ \\
\hline
\end{tabular}

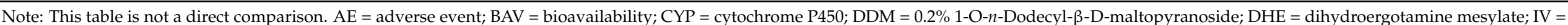

intravenous; SC = subcutaneous; US = United States. 


\subsection{Approved Products}

\subsubsection{IMITREX ${ }^{\circledR}$}

IMITREX (GlaxoSmithKline, Research Triangle Park, NC, USA) was approved in the US in 1997 as a nasal spray. It delivers sumatriptan, a serotonin receptor $\left(5-\mathrm{HT}_{1 \mathrm{~B} / 1 \mathrm{D}}\right)$ agonist, via a standard nasal spray and is indicated for the acute treatment of migraine with or without aura $[29,60,61]$. The recommended adult dose is 5,10 , or $20 \mathrm{mg}$, with $5 \mathrm{mg}$ and $20 \mathrm{mg}$ doses administered in a single spray and the $10 \mathrm{mg}$ dose in two sprays. Each $100 \mu \mathrm{L}$ spray of IMITREX contains 5 or $20 \mathrm{mg}$ sumatriptan in an aqueous buffered solution containing monobasic potassium phosphate National Formulary (NF), anhydrous dibasic sodium phosphate United States Pharmacopeia (USP), sulfuric acid NF, sodium hydroxide $\mathrm{NF}$, and purified water USP. The solution's $\mathrm{pH}$ is approximately 5.5 with an osmolality of 372 or $742 \mathrm{mOsmol}$ for the 5 and $20 \mathrm{mg}$ doses, respectively. The mean bioavailability following nasal administration was $17 \%$ relative to SC sumatriptan injection [29]. The maximum observed plasma concentration $\left(C_{\max }\right)$ was $69.5 \mathrm{ng} / \mathrm{mL}$ and $12.9 \mathrm{ng} / \mathrm{mL}$ following SC and nasal administration of sumatriptan, respectively, and the rate of absorption (measured as area under the serum concentration-time curve from zero to $t_{\max }, \mathrm{AUC}_{\mathrm{tmax}}$ ) was 9.0 and $7.4 \mathrm{~h}^{*} \mathrm{ng} / \mathrm{mL}$ for SC and nasal sumatriptan administration, respectively [79]. A total of eight randomized, double-blind, placebo-controlled clinical trials were performed to assess safety, efficacy, and tolerability of IMITREX nasal spray, of which five used the recommended dosing regimen and marketed formulation and are included in the United States Prescribing Information (USPI) [29]. In all trials, doses of 10 and $20 \mathrm{mg}$ were compared with placebo in the treatment of one to three migraine attacks, and in two trials, a 5 mg dose was also evaluated against placebo. Trial 5 was a multi-attack study, but only data for the first attack were reported in the USPI $[29,80]$. These studies demonstrated that a significantly greater percentage of patients achieved headache relief (defined as no or mild pain) at $2 \mathrm{~h}$ post-treatment with $20 \mathrm{mg}$ IMITREX nasal spray compared to those receiving the placebo in Trial $1(64 \%$ versus $25 \%, p<0.05)$, Trial $2(55 \%$ versus $25 \%, p<0.05)$, Trial 3 $(63 \%$ versus $35 \%, p<0.05)$, Trial 4 (62\% versus $29 \%, p<0.05)$, and Trial 5 (60\% versus $36 \%$, $p<0.05$ ) [29]. Similar observations extended to patients who received $10 \mathrm{mg}$ IMITREX nasal spray in Trial $1(46 \%$ versus $25 \%, p<0.05)$, Trial $2(44 \%$ versus $25 \%, p<0.05)$, Trial 3 $(54 \%$ versus $35 \%, p<0.05)$, Trial 4 ( $43 \%$ versus $29 \%, p<0.05)$, and Trial 5 ( $53 \%$ versus $36 \%$, $p<0.05)$. The most commonly reported AEs ( $\geq 1 \%$ of patients and greater than placebo) in those who received 20,10, or $5 \mathrm{mg}$ IMITREX nasal spray were similar although they occurred at different frequencies. Burning sensation was experienced in $1.4 \%, 0.6 \%$, and $0.4 \%$ of patients who received 20,10, and $5 \mathrm{mg}$, respectively. Disorder/discomfort of nasal cavity/sinuses was reported by $3.8 \%, 2.5 \%$, and $2.8 \%$ in those who received 20,10 , and $5 \mathrm{mg}$, respectively. Throat discomfort was reported by $2.4 \%, 1.8 \%$, and $0.8 \%$ in those who received 20,10, and $5 \mathrm{mg}$, respectively. Nausea and / or vomiting was reported by $13.5 \%$, $11.0 \%$, and $12.2 \%$ of those who received 20,10 , and $5 \mathrm{mg}$, respectively. Bad/unusual taste was reported by $24.5 \%, 19.3 \%$, and $13.5 \%$ in those who received 20,10 , and $5 \mathrm{mg}$, respectively. Finally, dizziness/vertigo was experienced by $1.4 \%, 1.7 \%$, and $1.0 \%$ of patients who received 20,10, and $5 \mathrm{mg}$, respectively [29]. No consistency of response data or long-term efficacy, safety, and tolerability data were found in published literature.

\subsubsection{MIGRANAL ${ }^{\circledR}$}

MIGRANAL (Bausch Health Companies Inc. or its affiliates, Bridgewater, NJ, USA) received US approval in 1997 and is a dihydroergotamine (DHE) mesylate nasal spray indicated for the acute treatment of migraine with or without aura [23,62]. It utilizes a traditional nasal delivery system that targets DHE mesylate to the lower nasal space [23,51]. In addition to DHE mesylate, each dose contains anhydrous caffeine, anhydrous dextrose, carbon dioxide, and purified water and its $\mathrm{pH}$ is approximately 4.4-5.4 in solution [62,81]. MIGRANAL acts by binding to serotonergic, dopaminergic, and adrenergic receptors. The recommended dosing is a single $0.5 \mathrm{mg} / \mathrm{mL}$ spray administered in each nostril, followed by one additional spray in each nostril 15 min later, for a total of 2 mg MIGRANAL 
delivered in four sprays. The mean bioavailability following nasal administration was $32 \%$ relative to injectable administration [62]. Several studies assessed the pharmacokinetics of MIGRANAL, with results demonstrating a $t_{\max }$ of $45 \mathrm{~min}$ and a dose-bioavailability relationship based on $\mathrm{C}_{\max }$ and AUC values of plasma DHE shown to be linear in the 0 to $4 \mathrm{mg}$ range [81]. Four randomized, double-blind, placebo-controlled, single-dose clinical trials were carried out in the US and are described in the USPI [62]. A significantly greater percentage of patients achieved headache relief (defined as no or mild pain) at $4 \mathrm{~h}$ with $2 \mathrm{mg}$ MIGRANAL compared to placebo in three of the four studies (Study 1, $70 \%$ versus $28 \%, p<0.001$; Study $2,56 \%$ versus $35 \%, p<0.01$; Study $3,48 \%$ versus $22 \%$, $p<0.01)[62,63]$. AEs reported by $\geq 1 \%$ of MIGRANAL-treated patients and that occurred more frequently than in the placebo group in the controlled studies reported in the USPI included rhinitis (26\%), nausea (10\%), altered sense of taste ( $8 \%)$, application site reactions $(6 \%)$, dizziness $(4 \%)$, and vomiting $(4 \%)$. It is important to note that the prescribing information for MIGRANAL includes a black box label reporting that serious and/or life-threatening peripheral ischemia has been associated with coadministration of DHE and CYP (cytochrome P450) 3A4 inhibitors [62]. No consistency of response data or long-term efficacy, safety, and tolerability data were found in published literature.

\subsection{3. $\mathrm{ZOMIG}^{\circledR}$}

ZOMIG (Amneal Pharmaceuticals, Bridgewater, NJ, USA) was approved in 2003 in the US $[64,65]$. It is a zolmitriptan-containing nasal spray indicated for the acute treatment of migraine with or without aura that has been shown to deliver zolmitriptan to the nasopharynx and lower nasal space $[33,64,82]$. It is a serotonin receptor agonist with a recommended starting dose of $2.5 \mathrm{mg}$; however, $5 \mathrm{mg}$ can be used if headache relief is not achieved with $2.5 \mathrm{mg}$. Each $100 \mu \mathrm{L}$ dose is supplied in an aqueous buffered solution containing anhydrous citric acid, disodium phosphate dodecahydrate USP, and purified water USP in addition to 2.5 or $5 \mathrm{mg}$ of zolmitriptan buffered to $\mathrm{pH}$ 5.0. The solution is hypertonic and its osmolarity is 360 to 420 and 420 to $470 \mathrm{mOsmol}$ for the 2.5 and $5 \mathrm{mg}$ dose, respectively. The mean bioavailability following nasal administration of ZOMIG is $102 \%$ relative to an oral tablet form [64]. The mean bioavailability of oral zolmitriptan is $49 \%$ relative to IV zolmitriptan [83]. A single randomized, outpatient, double-blind, dose-ranging, multi-attack placebo-controlled trial was performed in adults [66], and a randomized, double-blind, dose-ranging, single-attack placebo-controlled trial with a single-blind run-in period was performed in adolescents [67] in order to establish efficacy. A significantly greater percentage of patients achieved headache relief (defined as no or mild pain) at $2 \mathrm{~h}$ with $2.5 \mathrm{mg}$ ZOMIG compared to placebo in adults (55\% versus $31 \%, p<0.001)$ and in adolescents $(53 \%$ versus $39 \%, p<0.05)$. Similar results were observed with $5 \mathrm{mg}$ ZOMIG compared to placebo in adults ( $69 \%$ versus $31 \%, p<0.001$ ) and adolescents $(51 \%$ versus $39 \%, p<0.05)[64,66,67]$. The adult study revealed that the 2-hour headache response to ZOMIG was maintained consistently across the treatment of multiple attacks [66]. The most commonly reported AEs that occurred in $\geq 2 \%$ of adult or pediatric patients taking either 2.5 or $5 \mathrm{mg}$ ZOMIG in controlled studies were unusual taste (5 mg ZOMIG, 21\%; $2.5 \mathrm{mg}$ ZOMIG, 17\%), paresthesia (5 mg ZOMIG, 10\%; $2.5 \mathrm{mg}$ ZOMIG, $5 \%$ ), hyperesthesia (5 mg ZOMIG, 5\%; $2.5 \mathrm{mg}$ ZOMIG, 1\%), and somnolence (5 mg ZOMIG, $4 \%$; $2.5 \mathrm{mg}$ ZOMIG, 1\%) in adults and unusual taste (5 mg ZOMIG, 10\%; $2.5 \mathrm{mg}$ ZOMIG, $6 \%$ ) in adolescents [64]. Long-term studies revealed that $5 \mathrm{mg}$ ZOMIG provided consistent tolerability and efficacy $[68,84]$. A randomized, double-blind, parallel-group, multicenter study designed as a two-phase, crossover trial assessed long-term tolerability, efficacy, and consistency of response of ZOMIG over 1 year. Consistency of response was reported in $56.9 \%$ of patients taking $5 \mathrm{mg}$ ZOMIG who achieved a 2-hour headache response in $>75 \%$ of attacks over the course of 1 year [84]. An open-label, noncomparative, multicenter, Phase 3 study assessed the long-term safety and tolerability of $5 \mathrm{mg}$ ZOMIG in treating multiple migraine attacks over 1 year in migraine patients mostly naïve to triptan nasal sprays. A total of 538 patients treated 20,717 migraine attacks. The number of migraine attacks 
treated per patient was large (mean of 38.5 attacks per patient, with $79.7 \%$ of patients treating $\geq 10$ attacks) and the majority (58.6\%) demonstrated repeated and extended use of ZOMIG, treating a mean of $\geq 2$ attacks per 30 -day period for $\geq 6$ months. In this long-term safety and tolerability study, the only AEs to occur in $\geq 4 \%$ of attacks were unusual taste (19\%) and paresthesia (6.8\%) [68].

\subsubsection{ONZETRA ${ }^{\circledR} \mathrm{Xsail}^{\circledR}$}

ONZETRA Xsail (Currax Pharmaceuticals LLC, Morristown, NJ, USA) received US approval in 2016 [69]. It is a sumatriptan nasal powder contained in a disposable, single-use nosepiece containing $11 \mathrm{mg}$ sumatriptan base in a clear hypromellose capsule attached to a reusable delivery device body containing a mouthpiece and piercing mechanism. It is delivered into the nostril by blowing through the mouthpiece while the nosepiece is inserted into one nostril. The recommended dosing is achieved by delivering the contents of one $11 \mathrm{mg}$ nosepiece to each nostril for a total of $22 \mathrm{mg}$ [70]. Breath-powered nasal delivery of ONZETRA Xsail may allow for delivery of some sumatriptan to the upper nasal space [71]. Following nasal administration, the mean bioavailability of sumatriptan was $19 \%$ relative to SC injection [70]. A study comparing the pharmacokinetics of $20 \mathrm{mg}$ sumatriptan nasal spray (IMITREX nasal spray), $22 \mathrm{mg}$ sumatriptan nasal powder (ONZETRA Xsail), $100 \mathrm{mg}$ sumatriptan oral tablet (IMITREX tablet), and $6 \mathrm{mg}$ sumatriptan injection (IMITREX injection) found that administration of sumatriptan powder using the breath-powered technology of ONZETRA Xsail resulted in $27 \%$ higher $C_{\max }(20.8 \mathrm{vs} .16 .4 \mathrm{ng} / \mathrm{mL})$ and a $75 \%$ higher early exposure $\left(\mathrm{AUC}_{0-15 \mathrm{~min},} 2.1 \mathrm{vs} .1 .2 \mathrm{ng}\right.$ hour $/ \mathrm{mL}$ ) relative to the IMITREX nasal spray despite utilizing a $20 \%$ lower dose. However, relative to both the IMITREX tablet and injection, the peak $\left(\mathrm{C}_{\max }, 20.8,70.2,111.6 \mathrm{ng} / \mathrm{mL}\right.$ for ONZETRA Xsail, IMITREX tablet, and IMITREX injection, respectively) and overall exposure ( $\mathrm{AUC}_{0 \text {-inf }}, 64.9,308.8$, 128.2 ng*hour/mL for ONZETRA Xsail, IMITREX tablet, and IMITREX injection, respectively) following ONZETRA Xsail were lower [85]. One multicenter, randomized, doubleblind, placebo-controlled, single-attack study is described in the USPI, which reported that a significantly greater percentage of patients achieved headache relief (defined as no or mild pain) at $2 \mathrm{~h}$ with $22 \mathrm{mg}$ ONZETRA Xsail compared to placebo (68\% versus $45 \%, p<0.05)[70,72]$. Additional medications were allowed as rescue therapy $2 \mathrm{~h}$ after initial treatment. No headache symptoms (pain freedom and no nausea, no photophobia, and no phonophobia) were reported by $34 \%$ of patients who received $22 \mathrm{mg}$ ONZETRA Xsail compared to $17 \%$ of patients who received placebo $(p<0.05)$ at $2 \mathrm{~h}$ post-treatment. The most common AEs reported by $\geq 2 \%$ of patients were abnormal taste $(20 \%)$, nasal discomfort (11\%), rhinorrhea (5\%), and rhinitis (2\%) [70]. Consistency of response across three migraine attacks with $22 \mathrm{mg}$ ONZETRA Xsail was compared to $100 \mathrm{mg}$ oral sumatriptan in a randomized, multicenter, double-dummy, crossover, multi-attack, comparative efficacy study with two 12-week double-blind periods. Results revealed that a significantly greater percentage of patients had consistent pain relief and pain freedom with ONZETRA Xsail across multiple attacks at $30 \mathrm{~min}$ post-dose $(p<0.05)$ [73]. Another analysis of consistency from the same study mentioned above used a novel analytic technique and revealed a greater within-person consistency across multiple migraine headaches from 45 to $120 \mathrm{~min}$ post-dose with ONZETRA Xsail compared to oral sumatriptan [86]. Although it has been suggested that ONZETRA Xsail may deliver sumatriptan to the upper nasal space [71], no upper nasal safety assessment of olfactory mucosa structure and function by endoscopic evaluation or olfactory function testing, respectively, has been performed. No long-term efficacy, safety, or tolerability data were found in published literature.

\subsubsection{TOSYMRA ${ }^{\mathrm{TM}}$}

TOSYMRA (Upsher-Smith Laboratories, Maple Grove, MN, USA) was approved in 2019 in the US and is a nasal spray containing sumatriptan and a permeation-enhancing excipient $\left(0.2 \%\right.$ 1-O- $n$-Dodecyl- $\beta$-D-maltopyranoside (DDM, Intraveil $\left.\left.{ }^{\circledR}\right)\right)$ indicated for the acute treatment of migraine with or without aura $[74,75]$. Its site of drug deposition within 
the nasal cavity has not been explicitly stated in the literature. However, inclusion of the permeation-enhancing excipient, DDM, can enhance absorption and bioavailability of drugs delivered intranasally $[76,87,88]$. In addition to sumatriptan and DDM, each $100 \mu \mathrm{L}$ dose is supplied in an aqueous buffered solution containing citric acid monohydrate, potassium phosphate monobasic, sodium chloride, and anhydrous sodium phosphate dibasic. Its $\mathrm{pH}$ is approximately 5.0-6.0 and its osmolality is between 270 and $330 \mathrm{mOsmol}$ [74]. The recommended dose for TOSYMRA is $10 \mathrm{mg}$ administered in a single spray in one nostril, and the mean bioavailability following nasal administration of TOSYMRA $10 \mathrm{mg}$ is $87.7 \%$ relative to a $4 \mathrm{mg}$ SC injection and $58.4 \%$ relative to $6 \mathrm{mg}$ SC injection [74,77]. $\mathrm{C}_{\max }$ was $51.8,49.1$, and $72.8 \mathrm{ng} / \mathrm{mL}$ for TOSYMRA $10 \mathrm{mg}, 4 \mathrm{mg}$ SC injection, and $6 \mathrm{mg}$ SC injection, respectively, and $\mathrm{AUC}_{0-\infty}$ was 60.7, 69.2, and $103.8 \mathrm{ng}{ }^{*}$ hour/mL for TOSYMRA $10 \mathrm{mg}$, $4 \mathrm{mg}$ SC injection, and $6 \mathrm{mg}$ SC injection, respectively. Pharmacokinetic studies comparing a single dose of $10 \mathrm{mg}$ TOSYMRA to $20 \mathrm{mg}$ IMITREX demonstrated that TOSYMRA was more rapidly absorbed, with a $\mathrm{C}_{\max }$ of 63.9 and $21.4 \mathrm{ng} / \mathrm{mL}$ and an $\mathrm{AUC}_{0-2 \mathrm{hr}}$ of 48.4 and $24.7 \mathrm{ng}$ *hour/mL for TOSYMRA and IMITREX, respectively [76]. One multicenter, randomized, two-period, double-blind, placebo-controlled efficacy, safety, and tolerability study, in which patients were instructed to treat a single migraine episode using a single dose, demonstrated that a significantly greater percentage of patients achieved headache relief (defined as no or mild pain) at $2 \mathrm{~h}$ with $10 \mathrm{mg}$ TOSYMRA compared to placebo (83.3\% versus $55.0 \%, p=0.005)$. Application site pain (2-2.7\%) and dysgeusia (2-8.1\%) were the most commonly reported AEs [78]. An open-label, long-term safety and tolerability study performed in patients who experienced two to six migraine headaches per month revealed that TOSYMRA was well tolerated when used over 6 months. A total of $52.7 \%$ of patients reported medication-related events. The most common AEs reported by $\geq 2 \%$ of patients were application site pain (30.5\%), dysgeusia (21\%), application site reaction (5.4\%), upper respiratory infection (10.8\%), nasopharyngitis (7.2\%), and sinusitis (6.6\%). Additionally, most patients $(58 \%)$ reported the use of rescue medication at least once during the 6-month study [77]. No consistency of response data or long-term efficacy data were found in published literature.

\subsection{Comparator Studies between Nasal Routes of Delivery and Oral Tablets}

Studies have suggested that nasal delivery of some triptans provides more rapid onset with greater efficacy compared with oral triptan tablets $[66,71]$. The COMPASS study was a randomized, active-comparator, double-dummy, crossover, multi-attack study that compared the efficacy, tolerability, and safety of breath-powered nasal delivery containing a low dose (22 mg, AVP-825 (ONZETRA Xsail)) of sumatriptan versus oral delivery (100 mg) of sumatriptan. Results showed that ONZETRA plus placebo pill (ONZETRA) resulted in a significantly greater reduction in migraine pain intensity compared to $100 \mathrm{mg}$ oral sumatriptan plus placebo nasal product (oral sumatriptan) in the first 30 min post-dose (least squares (LS) mean for summed pain intensity differences (SPID) $=10.8$ versus 7.4 , adjusted mean difference 3.4, $p<0.001$ ). Greater rates of pain relief occurred with ONZETRA compared to oral sumatriptan at each time point measured: $15 \mathrm{~min}(27.9 \%$ versus $20.9 \%, p=0.007), 30 \mathrm{~min}(53.8 \%$ versus $38.7 \%, p<0.001), 45 \mathrm{~min}(65.0 \%$ versus $53.9 \%, p<0.001), 60 \mathrm{~min}(72.1 \%$ versus $62.6 \%, p<0.001)$, and $90 \mathrm{~min}(77.4 \%$ versus $72.0 \%, p=0.03)$. Additionally, greater rates of pain freedom occurred with ONZETRA compared to oral sumatriptan at $15 \mathrm{~min}(7.2 \%$ versus $3.7 \%, p=0.008), 30 \mathrm{~min}(18.2 \%$ versus $10.8 \%, p<0.001), 45 \mathrm{~min}(31.0 \%$ versus $21.3 \%, p<0.001), 60 \mathrm{~min}(41.2 \%$ versus $32.9 \%, p=0.002)$, and $90 \mathrm{~min}(52.8 \%$ versus $44.9 \%, p=0.006)$. It was postulated that early rates of pain relief may reflect quick systemic absorption of the sumatriptan powder delivered to the highly absorptive upper nasal cavity via the breath-powered device. Rates of pain relief and freedom at $2 \mathrm{~h}$ and sustained pain freedom from 2 to $48 \mathrm{~h}$ for ONZETRA were comparable to oral sumatriptan. This study also demonstrated that ONZETRA was well tolerated, as no serious AEs occurred, and most AEs were mild in severity. The most commonly reported AEs were abnormal product taste (26\% ONZETRA versus 3.9\% 
$100 \mathrm{mg}$ oral sumatriptan) and nasal discomfort (15.5\% ONZETRA versus 1.3\% $100 \mathrm{mg}$ oral sumatriptan). Additionally, ONZETRA displayed significantly fewer triptan-related AEs, such as a warm or burning sensation, feeling of heaviness, pressure, tightness, or numbness, compared to $100 \mathrm{mg}$ oral sumatriptan $(2 \%$ versus $5 \%, p=0.02)$ [71].

A randomized, double-blind, placebo-controlled, multicenter, dose-ranging study compared the efficacy and tolerability of fixed doses of zolmitriptan administered via a nasal spray (ZOMIG) to both placebo and oral zolmitriptan tablets. Results revealed that each dose of ZOMIG produced a greater 2-hour headache response (no or mild pain; 70.3\%, $58.6 \%, 54.8 \%$, and $41.5 \%$ for ZOMIG 5, 2.5, 1 , and $0.5 \mathrm{mg}$, respectively) compared with $30.6 \%$ for placebo (all $p<0.001$ versus placebo). The 2-hour headache response rate for $5 \mathrm{mg}$ ZOMIG was significantly higher than that of the $2.5 \mathrm{mg}$ oral zolmitriptan tablet $(70.3 \%$ versus $61.3 \%, p<0.05)$. ZOMIG $5 \mathrm{mg}$ provided a 2 -hour headache response $(11.1 \%)$ that was statistically superior to both placebo (5.4\%) and the $2.5 \mathrm{mg}$ oral zolmitriptan tablet $(5.4 \%)$ at $15 \mathrm{~min}$ after administration $(p<0.05)$ [66].

\subsection{Products in Development}

\subsubsection{STS101}

A nasal DHE powder delivered from a disposable nasal delivery device (STS101) is currently in development by Satsuma Pharmaceuticals (South San Francisco, CA, USA). A Phase 1, randomized, open-label, safety, tolerability, and comparative bioavailability study of STS101 demonstrated quick systemic absorption, attaining effective DHE plasma concentrations $(>1000 \mathrm{pg} / \mathrm{mL})$ within $10 \mathrm{~min}$. Although the pharmacokinetics of STS101 demonstrated values that were 2.3-fold higher than those of MIGRANAL, it utilized a $6 \mathrm{mg}$ dose that was 300\% of the approved MIGRANAL $2 \mathrm{mg}$ dose [89]. The results of topline data from the EMERGE trial, a Phase 3, multicenter, single-dose, randomized, double-blind, placebo-controlled, parallel-group efficacy study, showed that although numerical differences were in favor of STS101, the study did not demonstrate statistically significant differences between dosage strengths $(4$ and $6 \mathrm{mg}$ ) compared to placebo on coprimary endpoints of pain and most bothersome symptom freedom (among photophobia, phonophobia, or nausea) at $2 \mathrm{~h}$ post-administration [90].

\subsubsection{INP104}

Impel NeuroPharma (Seattle, WA, USA) currently has a novel drug-device combination product in development (and submitted a new drug application (NDA) in November 2020) that targets delivery of liquid DHE mesylate to the upper nasal cavity using a Precision Olfactory Delivery (POD ${ }^{\circledR}$ ) device (INP104). The POD technology has been developed to address the low bioavailability and variability in nasal administration seen with traditional nasal sprays. The drug delivery of INP104 to the upper nasal space takes advantage of the olfactory region's abundant vascularity and avoids drug loss due to the drug dripping out of the nose or clearance to the nasopharynx, thereby increasing systemic availability $[22,23,34,44,50,51]$. A Phase 1 , open-label, randomized, three-period, three-way crossover study evaluated the bioavailability of INP104. Healthy subjects received single doses of (A) INP104 $1.45 \mathrm{mg}$, (B) IV DHE mesylate $1 \mathrm{mg}$, and (C) DHE mesylate nasal spray $2 \mathrm{mg}$ (MIGRANAL) in one of six sequences with a 7-day washout between treatments. A $10 \mathrm{mg}$ metoclopramide pretreatment was administered to all subjects [51]. Results revealed that exposure to DHE following administration of INP104 fell between that of IV DHE and MIGRANAL, with a four-fold increase in $C_{\max }$ and a three-fold increase in exposure (measured as $\mathrm{AUC}_{0 \text {-inf }}$ ) compared to MIGRANAL, despite using an identical formulation, and $<75 \%$ of the dose in the same healthy adult volunteers. INP104 produced a plasma DHE level that was comparable to that of IV DHE after only $30 \mathrm{~min}$. The absolute bioavailability for INP104 was four times as much as that of MIGRANAL (58.9\% versus $15.2 \%$ ). Additionally, INP104 administration demonstrated less variability (coefficient of variation $(\mathrm{CV} \%)$ ) in $\mathrm{C}_{\max }$ at $53.3 \%$ vs. $79.4 \%$ and in $\mathrm{AUC}_{0 \text {-inf }}$ at $41.8 \%$ vs. $74.7 \%$ compared to MIGRANAL administration, suggesting more consistent drug delivery with the POD 
device [51]. INP104 was well tolerated, producing a tolerability profile comparable to that of MIGRANAL, but with less nausea than what is reported for MIGRANAL ( $10 \%$ in the MIGRANAL USPI) [51,62]. Importantly, drug leakage from the nose was only reported by $32 \%$ of INP104 users, compared to 77\% of MIGRANAL users [51]. A Phase 3, interventional, open-label, single-group assignment study assessing the long-term safety and tolerability of chronic, intermittent use of INP104 over 24 weeks, with a treatment continuation to 52 weeks for a subset of users, was recently completed (STOP 301). The study revealed INP104 to be well tolerated over the course of a year [91], and detailed study results will be reported in an upcoming publication this year. Importantly, rates of nausea in patients who self-administered at least one dose of INP104 were low considering pretreatment with an antiemetic was not required. Of the total doses of INP104 administered over 52 weeks, INP104-related nausea was reported at a rate of less than $1 \%$.

\section{Does Nasal Delivery Address Patient Needs?}

A 2017 study revealed that $95 \%$ of patients have at least one unmet need from their acute medication used to treat migraine. Many patients (74.1\%) reported unmet needs associated with inadequate treatment response. Specifically, inadequate pain freedom at $2 \mathrm{~h}(48.1 \%)$ and headache recurrence within $24 \mathrm{~h}$ of initial relief $(38 \%)$ were the two most common unmet needs associated with treatment. Patients $(89.5 \%)$ also reported attack-related unmet needs, including the lack of rapid onset (65.3\%) and headache-related disability (55.6\%) [92]. A recent survey that assessed which medication attributes were of most interest to patients revealed that an ideal acute medication would be fast-acting (15-30 $\mathrm{min}$ ) and long-lasting (12-24 h), would provide complete or near complete pain relief, could be taken at any time during the migraine, and would have few or no side effects. Patients also reported that they were willing to accept minor side effects as a trade-off for increased speed and efficacy [93]. These results suggest that the current treatment approach for many migraine patients is suboptimal and may explain treatment dissatisfaction [92,93]. Although oral medications are often effective, their onset of action may be slow due to gastric stasis that may be exacerbated in a migraine attack and the rate of subsequent absorption from the small intestine, and these delays may be worse for patients with nausea or vomiting. Such symptoms, which can be bothersome, even the most bothersome, may discourage patients from taking oral medication, and once vomiting has occurred after oral medication has been taken, may cause anxiety about whether to take a repeat dose. Administration of drugs via nasal delivery may overcome some of the limitations of oral administration, providing rapid absorption and resulting in swift onset of action $[11,19,66]$.

Nasal delivery can provide an attractive avenue to achieve the consensus goals of rapid and consistent freedom from pain (Table 2). Rates of early pain relief and pain freedom favor nasal delivery over oral delivery for some triptans, with nasal delivery offering relief in as little as $15 \mathrm{~min}$ post-dose [71-73]. Additionally, nasal delivery can result in less headache-related disability and migraine-associated symptoms compared to oral delivery [71]. Nasal delivery offers consistency in headache response and lasting, durable relief from pain $[66,71,73]$. Finally, nasal delivery provides patients with the power to decide when and where to take treatment from easy-to-use, portable devices that may allow them to take control of their disease [22,23]. 
Table 2. How nasal delivery of acute treatments for migraine addresses attributes important to patients.

\begin{tabular}{|c|c|c|}
\hline Attributes Desired by Patients & Upper Nasal Space Delivery & Traditional Nasal Delivery \\
\hline Speed of onset-headache relief in $<30 \mathrm{~min}$ [93-95] & - $\quad$ Relief reported at $15 \min [72,73,85]$ & - $\quad$ Relief reported at $15-120 \min [29,62,66]$ \\
\hline Provides complete or near complete pain relief $[94,95]$ & $\begin{array}{l}\text { - } \quad \text { Pain freedom reported at } 30 \mathrm{~min} \text { to } 2 \mathrm{~h} \text { post-dose } \\
\text { - } \quad \text { Sustained pain freedom through } 48 \mathrm{~h} \text { post-dose }[71,72]\end{array}$ & $\begin{array}{l}\text { - Pain freedom/relief reported at } 30 \mathrm{~min} \text { to } 4 \mathrm{~h} \text { post-dose } \\
{[29,62,66]}\end{array}$ \\
\hline Few or minor side effects [94] & $\begin{array}{l}\text { - Fewer AEs than oral delivery [71] } \\
\text { - Commonly reported AEs include abnormal product taste, } \\
\text { nasal discomfort, rhinorrhea, and rhinitis }[71,72]\end{array}$ & $\begin{array}{l}\text { May have high incidence of AEs local to the nasopharynx } \\
\text { (i.e., intranasal paresthesia and unusual taste), with other } \\
\text { AEs occurring at slightly higher rates overall compared to } \\
\text { oral delivery [66] } \\
\text { Commonly reported AEs include nausea and/or vomiting, } \\
\text { unusual taste, paresthesia, application site reactions, rhinitis, } \\
\text { dysgeusia, throat irritation, intranasal paresthesia, } \\
\text { hyperesthesia, dizziness, somnolence, and pharyngitis } \\
{[29,62,64,66]}\end{array}$ \\
\hline Relief from headache-associated symptoms [95] & - $\quad$ MBS relief as early as $10-15$ min post-dose [71] & MBS relief at $2-4 \mathrm{~h}$ post-dose $[29,62,66]$ \\
\hline Ability to carry on with the day [94] & $\begin{array}{l}\text { - Majority of patients reported return to normal activities } \\
\text { faster than their previous prescription [96] }\end{array}$ & $\begin{array}{l}\text { - Allows for continuation of normal activities by } 2 \mathrm{~h} \text { in most } \\
\text { patients }[66,84]\end{array}$ \\
\hline
\end{tabular}




\section{Conclusions}

Nasal delivery is a well-established route of drug administration. However, the majority of nasal sprays for the acute treatment of migraine target the lower nasal space, where absorption is limited due to quick elimination from nasal drip or clearance to the nasopharynx and rapid mucociliary clearance. Upper nasal delivery provides welltolerated, rapid, and efficient drug absorption, and improved bioavailability compared to lower nasal delivery, ensuring quick and durable migraine relief. Delivery of drugs to the highly vascularized and absorptive upper nasal space may be an optimal route for migraine therapy and, although few products targeting the upper nasal space exist, this technology expands the possibilities of nasal drug delivery with an easy-to-use, portable device.

Author Contributions: Conceptualization, V.M., J.H., S.K.A. and S.B.S.; methodology, V.M., J.H., S.K.A. and S.B.S.; software, not applicable.; validation, V.M., J.H., S.K.A. and S.B.S.; formal analysis, not applicable; investigation, V.M., J.H., S.K.A. and S.B.S.; resources, J.H., S.K.A. and S.B.S.; data curation, V.M., J.H., S.K.A. and S.B.S.; writing-original draft preparation, V.M., J.H., S.K.A. and S.B.S.; writing-review and editing, V.M., J.H., S.K.A. and S.B.S.; visualization, V.M., J.H., S.K.A. and S.B.S.; supervision, S.K.A. and S.B.S.; project administration, S.K.A. and S.B.S.; funding acquisition, J.H., S.K.A. and S.B.S. All authors have read and agreed to the published version of the manuscript.

Funding: This work received no external funding.

Institutional Review Board Statement: Not applicable for this review of published work.

Informed Consent Statement: Not applicable for this review of published work.

Data Availability Statement: Not applicable for this review of published work.

Acknowledgments: Writing and editorial assistance was provided by IMPRINT Science, New York, NY, and supported by Impel NeuroPharma. The authors are fully responsible for the content, editorial decisions, and opinions expressed in this article.

Conflicts of Interest: Vincent Martin is a consultant for Eli Lilly and Company, Amgen, Teva Pharmaceuticals, Theranica Bio-Electronics, Biohaven Pharmaceuticals, and AbbVie, and is a speaker for AbbVie, Teva Pharmaceuticals, Biohaven Pharmaceuticals, Amgen, and Eli Lilly and Company. John Hoekman, Sheena K. Aurora, and Stephen B. Shrewsbury are full-time employees of Impel NeuroPharma and are stockholders in Impel NeuroPharma. John Hoekman and Stephen B. Shrewsbury are also officers of Impel NeuroPharma.

\footnotetext{
Abbreviations

$\mathrm{AE}=$ adverse event; $\mathrm{API}=$ active pharmaceutical ingredient; $\mathrm{AUC}_{0 \text {-inf }}=$ area under the drug concentration-time curve from time 0 to infinity; $\mathrm{AUC}_{\mathrm{tmax}}=$ area under the serum concentrationtime curve from zero to $t_{\max } ; \mathrm{BAV}=$ bioavailability; $\mathrm{C}_{\max }=$ maximum observed plasma concentration; $\mathrm{CV} \%=$ coefficient of variation; $\mathrm{CYP}=$ cytochrome $\mathrm{P} 450 ; \mathrm{DDM}=n$-Dodecyl- $\beta$-D-maltopyranoside; $\mathrm{DHE}=$ dihydroergotamine mesylate; FSS = full safety set; GI = gastrointestinal; $\mathrm{IM}=$ intramuscular; IV = intravenous; $\mathrm{LM}=$ least squares mean; NDA = new drug application; $\mathrm{NF}=$ National Formulary; POD = Precision Olfactory Delivery; SC = subcutaneous; SPID = summed pain intensity differences; TEAE = treatment-emergent adverse event; $t_{\max }=$ time to maximum plasma concentration; UAS = unilateral cranial autonomic symptoms; US = United States; USP = United States Pharmacopeia; USPI $=$ United States Prescribing Information .
}

\section{References}

1. Leonardi, M.; Raggi, A. A narrative review on the burden of migraine: When the burden is the impact on people's life. J. Headache Pain 2019, 20, 41. [CrossRef]

2. Raggi, A.; Giovannetti, A.M.; Quintas, R.; D’Amico, D.; Cieza, A.; Sabariego, C.; Bickenbach, J.E.; Leonardi, M. A systematic review of the psychosocial difficulties relevant to patients with migraine. J. Headache Pain 2012, 13, 595-606. [CrossRef]

3. Buse, D.C.; Scher, A.I.; Dodick, D.W.; Reed, M.L.; Fanning, K.M.; Manack Adams, A.; Lipton, R.B. Impact of Migraine on the Family: Perspectives of People With Migraine and Their Spouse/Domestic Partner in the CaMEO Study. Mayo Clin. Proc. 2016. [CrossRef] 
4. Global, regional, and national burden of migraine and tension-type headache, 1990-2016: A systematic analysis for the Global Burden of Disease Study 2016. Lancet Neurol. 2018, 17, 954-976. [CrossRef]

5. Lipton, R.B.; Munjal, S.; Alam, A.; Buse, D.C.; Fanning, K.M.; Reed, M.L.; Schwedt, T.J.; Dodick, D.W. Migraine in America Symptoms and Treatment (MAST) Study: Baseline Study Methods, Treatment Patterns, and Gender Differences. Headache 2018, 58, 1408-1426. [CrossRef]

6. Migraine Research Foundation. Migraine Facts. Available online: https://migraineresearchfoundation.org/about-migraine/ migraine-facts (accessed on 27 July 2020).

7. Cooke, L.J.; Becker, W.J. Migraine prevalence, treatment and impact: The Canadian women and migraine study. Can. J. Neurol. Sci. 2010, 37, 580-587. [CrossRef]

8. Holland, S.; Fanning, K.M.; Serrano, D.; Buse, D.C.; Reed, M.L.; Lipton, R.B. Rates and reasons for discontinuation of triptans and opioids in episodic migraine: Results from the American Migraine Prevalence and Prevention (AMPP) study. J. Neurol. Sci. 2013, 326, 10-17. [CrossRef]

9. Lipton, R.B.; Hutchinson, S.; Ailani, J.; Reed, M.L.; Fanning, K.M.; Manack Adams, A.; Buse, D.C. Discontinuation of Acute Prescription Medication for Migraine: Results from the Chronic Migraine Epidemiology and Outcomes (CaMEO) Study. Headache 2019, 59, 1762-1772. [CrossRef]

10. Homayun, B.; Lin, X.; Choi, H.J. Challenges and Recent Progress in Oral Drug Delivery Systems for Biopharmaceuticals. Pharmaceutics 2019, 11, 129. [CrossRef]

11. Djupesland, P.G.; Messina, J.C.; Mahmoud, R.A. Breath powered nasal delivery: A new route to rapid headache relief. Headache 2013, 53 (Suppl. 2), 72-84. [CrossRef] [PubMed]

12. Price, G.; Patel, D.A. Drug Bioavailability; StatPearls: Treasure Island, FL, USA, 2020.

13. Becker, D.E. Drug therapy in dental practice: General principles. Part 1-Pharmacokinetic considerations. Anesth. Prog. 2006, 53, 140-145. [CrossRef]

14. Volans, G.N. Migraine and drug absorption. Clin. Pharm. 1978, 3, 313-318. [CrossRef]

15. Brazzell, R.K.; Colburn, W.A. Controversy I: Patients or healthy volunteers for pharmacokinetic studies? J. Clin Pharmacol. 1986, 26, 242-247. [CrossRef]

16. Aurora, S.K.; Kori, S.H.; Barrodale, P.; McDonald, S.A.; Haseley, D. Gastric stasis in migraine: More than just a paroxysmal abnormality during a migraine attack. Headache 2006, 46, 57-63. [CrossRef] [PubMed]

17. Aurora, S.K.; Rozen, T.D.; Kori, S.H.; Shrewsbury, S.B. A randomized, double blind, placebo-controlled study of MAP0004 in adult patients with migraine. Headache 2009, 49, 826-837. [CrossRef]

18. Becker, W.J. Acute migraine treatment in adults. Headache 2015, 55, 778-793. [CrossRef]

19. Rapoport, A.M.; Freitag, F.; Pearlman, S.H. Innovative delivery systems for migraine: The clinical utility of a transdermal patch for the acute treatment of migraine. CNS Drugs 2010, 24, 929-940. [CrossRef]

20. Marmura, M.J.; Silberstein, S.D.; Schwedt, T.J. The acute treatment of migraine in adults: The American Headache Society Evidence Assessment of Migraine Pharmacotherapies. Headache 2015, 55, 3-20. [CrossRef] [PubMed]

21. Jin, J.F.; Zhu, L.L.; Chen, M.; Xu, H.M.; Wang, H.F.; Feng, X.Q.; Zhu, X.P.; Zhou, Q. The optimal choice of medication administration route regarding intravenous, intramuscular, and subcutaneous injection. Patient Prefer. Adherence 2015, 9, 923-942. [CrossRef] [PubMed]

22. Musumeci, T.; Bonaccorso, A.; Puglisi, G. Epilepsy Disease and Nose-to-Brain Delivery of Polymeric Nanoparticles: An Overview. Pharmaceutics 2019, 11, 118. [CrossRef] [PubMed]

23. Silberstein, S.D.; Shrewsbury, S.B.; Hoekman, J. Dihydroergotamine (DHE)—Then and Now: A Narrative Review. Headache 2020, 60, 40-57. [CrossRef] [PubMed]

24. Arslan, H.H.; Tokgoz, E.; Yildizoglu, U.; Durmaz, A.; Bek, S.; Gerek, M. Evaluation of the changes in the nasal cavity during the migraine attack. J. Craniofac. Surg. 2014, 25, e446-e449. [CrossRef] [PubMed]

25. Ku, M.; Silverman, B.; Prifti, N.; Ying, W.; Persaud, Y.; Schneider, A. Prevalence of migraine headaches in patients with allergic rhinitis. Ann. Allergy Asthma Immunol. 2006, 97, 226-230. [CrossRef]

26. Martin, V.T.; Fanning, K.M.; Serrano, D.; Buse, D.C.; Reed, M.L.; Bernstein, J.A.; Lipton, R.B. Chronic rhinitis and its association with headache frequency and disability in persons with migraine: Results of the American Migraine Prevalence and Prevention (AMPP) Study. Cephalalgia 2014, 34, 336-348. [CrossRef] [PubMed]

27. Barbanti, P.; Aurilia, C.; Dall'Armi, V.; Egeo, G.; Fofi, L.; Bonassi, S. The phenotype of migraine with unilateral cranial autonomic symptoms documents increased peripheral and central trigeminal sensitization. A case series of 757 patients. Cephalalgia 2016, 36, 1334-1340. [CrossRef]

28. Fornazieri, M.A.; Neto, A.R.; de Rezende Pinna, F.; Gobbi Porto, F.H.; de Lima Navarro, P.; Voegels, R.L.; Doty, R.L. Olfactory symptoms reported by migraineurs with and without auras. Headache 2016, 56, 1608-1616. [CrossRef]

29. IMITREX®Nasal Spray [Package Insert]. GlaxoSmithKline, Inc., 2017. Available online: https://gskpro.com/content/dam/ global/hcpportal/en_US/Prescribing_Information/Imitrex_Nasal_Spray/pdf/IMITREX-NASAL-SPRAY-PI-PIL.PDF (accessed on 11 March 2021).

30. Rapoport, A.M.; Bigal, M.E.; Tepper, S.J.; Sheftell, F.D. Intranasal medications for the treatment of migraine and cluster headache. CNS Drugs 2004, 18, 671-685. [CrossRef] 
31. Schönbach, C. Respiratory tract, upper and lower. In Encyclopedia of Systems Biology; Werner Dubitzky, O.W., Cho, K.-H., Yokota, H., Eds.; Springer Link: Berlin/Heidelberg, Germany, 2013; pp. 1-3. [CrossRef]

32. Person, A.; Mintz, M. Current Clinical Practice: Disorders of the Respiratory Tract: Common Challenges in Primary Care; Humana Press: Totowa, NJ, USA, 2006.

33. Hoekman, J.; Brunelle, A.; Hite, M.; Kim, P.; Fuller, C. SPECT imaging of direct nose-to-brain transfer of MAG-3 in man. In Proceedings of the American Association of Pharmaceutical Scientists Annual Meeting, San Antonio, TX, USA, 10-14 September 2013, W4009.

34. Hoekman, J.; Ray, S.; Aurora, S.K.; Shrewsbury, S.B. The Upper Nasal Space-A Novel Delivery Route Ideal for Central Nervous System Drugs. US Neurol. 2020, 16, 25-31. [CrossRef]

35. Crowe, T.P.; Greenlee, M.H.W.; Kanthasamy, A.G.; Hsu, W.H. Mechanism of intranasal drug delivery directly to the brain. Life Sci. 2018, 195, 44-52. [CrossRef]

36. Djupesland, P.G.; Messina, J.C.; Mahmoud, R.A. The nasal approach to delivering treatment for brain diseases: An anatomic, physiologic, and delivery technology overview. Ther. Deliv. 2014, 5, 709-733. [CrossRef]

37. Ganger, S.; Schindowski, K. Tailoring Formulations for Intranasal Nose-to-Brain Delivery: A Review on Architecture, PhysicoChemical Characteristics and Mucociliary Clearance of the Nasal Olfactory Mucosa. Pharmaceutics 2018, 10, 116. [CrossRef] [PubMed]

38. Edvinsson, J.C.A.; Vigano, A.; Alekseeva, A.; Alieva, E.; Arruda, R.; De Luca, C.; D’Ettore, N.; Frattale, I.; Kurnukhina, M.; Macerola, N.; et al. The fifth cranial nerve in headaches. J. Headache Pain 2020, 21, 65. [CrossRef]

39. Noseda, R.; Jakubowski, M.; Kainz, V.; Borsook, D.; Burstein, R. Cortical projections of functionally identified thalamic trigeminovascular neurons: Implications for migraine headache and its associated symptoms. J. Neurosci. 2011, 31, 14204-14217. [CrossRef] [PubMed]

40. Ashina, M.; Hansen, J.M.; Do, T.P.; Melo-Carrillo, A.; Burstein, R.; Moskowitz, M.A. Migraine and the trigeminovascular system-40 years and counting. Lancet Neurol. 2019, 18, 795-804. [CrossRef]

41. Noseda, R.; Burstein, R. Migraine pathophysiology: Anatomy of the trigeminovascular pathway and associated neurological symptoms, cortical spreading depression, sensitization, and modulation of pain. Pain 2013, 154 (Suppl. 1), S44-S53. [CrossRef] [PubMed]

42. Chadha, D.S.; Anadure, R.K. Handbook of Medical Emergencies, 2019th ed.; Department of Medicine Command Hospital (AF): Bangalore, India; Karnataka, India, 2019.

43. Helwany, M.; Bordoni, B. Neuroanatomy, Cranial Nerve 1 (Olfactory). In StatPearls; StatPearls Publishing Copyright $\odot 2020$ StatPearls Publishing LLC.: Treasure Island, FL, USA, 2020.

44. Lochhead, J.J.; Thorne, R.G. Intranasal delivery of biologics to the central nervous system. Adv. Drug Deliv. Rev. 2012, 64, 614-628. [CrossRef]

45. Ladel, S.; Schlossbauer, P.; Flamm, J.; Luksch, H.; Mizaikoff, B.; Schindowski, K. Improved In Vitro Model for Intranasal Mucosal Drug Delivery: Primary Olfactory and Respiratory Epithelial Cells Compared with the Permanent Nasal Cell Line RPMI 2650. Pharmaceutics 2019, 11,367. [CrossRef]

46. Harkema, J.R.; Carey, S.A.; Wagner, J.G. The nose revisited: A brief review of the comparative structure, function, and toxicologic pathology of the nasal epithelium. Toxicol. Pathol. 2006, 34, 252-269. [CrossRef] [PubMed]

47. Harkema, J.R.; Plopper, C.G.; Hyde, D.M.; St George, J.A. Regional differences in quantities of histochemically detectable mucosubstances in nasal, paranasal, and nasopharyngeal epithelium of the bonnet monkey. J. Histochem. Cytochem. 1987, 35, 279-286. [CrossRef] [PubMed]

48. Mogensen, C.; Tos, M. Density of goblet cells on normal adult nasal turbinates. Anat. Anz. 1977, 142, 322-330. [PubMed]

49. Morgan, K.T.; Jiang, X.Z.; Patterson, D.L.; Gross, E.A. The nasal mucociliary apparatus. Correlation of structure and function in the rat. Am. Rev. Respir. Dis. 1984, 130, 275-281. [CrossRef] [PubMed]

50. Hoekman, J.D.; Ho, R.J. Enhanced analgesic responses after preferential delivery of morphine and fentanyl to the olfactory epithelium in rats. Anesth. Analg. 2011, 113, 641-651. [CrossRef]

51. Shrewsbury, S.B.; Jeleva, M.; Satterly, K.H.; Lickliter, J.; Hoekman, J. STOP 101: A Phase 1, Randomized, Open-Label, Comparative Bioavailability Study of INP104, Dihydroergotamine Mesylate (DHE) Administered Intranasally by a I123 Precision Olfactory Delivery (POD) Device, in Healthy Adult Subjects. Headache 2019, 59, 394-409. [CrossRef] [PubMed]

52. Watelet, J.B.; Van Cauwenberge, P. Applied anatomy and physiology of the nose and paranasal sinuses. Allergy 1999, 54 (Suppl. 57), 14-25. [CrossRef]

53. Rusznak, C.; Devalia, J.L.; Lozewicz, S.; Davies, R.J. The assessment of nasal mucociliary clearance and the effect of drugs. Respir. Med. 1994, 88, 89-101. [CrossRef]

54. Escada, P.A.; Lima, C.; da Silva, J.M. The human olfactory mucosa. Eur. Arch. Otorhinolaryngol. 2009, 266, 1675-1680. [CrossRef]

55. Merkus, F.W.; Verhoef, J.C.; Schipper, N.G.; Marttin, E. Nasal mucociliary clearance as a factor in nasal drug delivery. Adv. Drug Deliv. Rev. 1998, 29, 13-38. [CrossRef]

56. Ugwoke, M.I.; Agu, R.U.; Verbeke, N.; Kinget, R. Nasal mucoadhesive drug delivery: Background, applications, trends and future perspectives. Adv. Drug Deliv. Rev. 2005, 57, 1640-1665. [CrossRef]

57. Schipper, N.G.; Verhoef, J.C.; Merkus, F.W. The nasal mucociliary clearance: Relevance to nasal drug delivery. Pharm. Res. 1991, 8, 807-814. [CrossRef] 
58. Upadhyay, S.; Parikh, A.; Joshi, P.; Upadhyay, U.; Chotai, N. Intranasal drug delivery system-A glimpse to become maestro. J. Appl. Pharm. Sci. 2011, 1, 34-44.

59. Gao, M.; Shen, X.; Mao, S. Factors influencing drug deposition in the nasal cavity upon delivery via nasal sprays. J. Pharm. Investig. 2020, 50, 251-259. [CrossRef]

60. Djupesland, P.G. Nasal drug delivery devices: Characteristics and performance in a clinical perspective-A review. Drug Deliv. Transl. Res. 2013, 3, 42-62. [CrossRef]

61. Drug Approval Package. IMITREX (sumatriptan) Nasal Spray. Available online: https://www.accessdata.fda.gov/drugsatfda_ docs/nda/97/020626ap-1.pdf (accessed on 11 March 2021).

62. MIGRANAL®[Package Insert]. Bausch Health Companies, Inc., 2019. Available online: https://www.bauschhealth.com/Portals/ 25/Pdf/PI/Migranal-PI.pdf (accessed on 24 February 2021).

63. Gallagher, R.M.; Dihydroergotamine Working Group. Acute treatment of migraine with dihydroergotamine nasal spray. Arch. Neurol. 1996, 53, 1285-1291. [CrossRef] [PubMed]

64. ZOMIG®Nasal Spray [Package Insert]. Amneal Pharmaceuticals LLC, 2019. Available online: https:/ /www.accessdata.fda.gov/ drugsatfda_docs/label/2013/021450s007lbl.pdf (accessed on 16 March 2021).

65. Drug Approval Package. ZOMIG (Zolmitriptan) Nasal Spray. Available online: https://www.accessdata.fda.gov/drugsatfda_ docs/nda/2003/21-450_Zomig.cfm (accessed on 16 November 2020).

66. Charlesworth, B.R.; Dowson, A.J.; Purdy, A.; Becker, W.J.; Boes-Hansen, S.; Färkkilä, M. Speed of onset and efficacy of zolmitriptan nasal spray in the acute treatment of migraine: A randomised, double-blind, placebo-controlled, dose-ranging study versus zolmitriptan tablet. CNS Drugs 2003, 17, 653-667. [CrossRef] [PubMed]

67. Winner, P.; Farkas, V.; Štillová, H.; Woodruff, B.; Liss, C.; Lillieborg, S.; Raines, S. Efficacy and tolerability of zolmitriptan nasal spray for the treatment of acute migraine in adolescents: Results of a randomized, double-blind, multi-center, parallel-group study (TEENZ). Headache 2016, 56, 1107-1119. [CrossRef]

68. Dowson, A.J.; Charlesworth, B.R.; Green, J.; Farkkila, M.; Diener, H.C.; Hansen, S.B.; Gawel, M.; Index Study Group. Zolmitriptan nasal spray exhibits good long-term safety and tolerability in migraine: Results of the INDEX trial. Headache 2005, 45, 17-24. [CrossRef]

69. ONZETRA Xsail (Sumatriptan) Nasal Powder. Available online: https://www.accessdata.fda.gov/drugsatfda_docs/nda/2016 /206099Orig1s000TOC.cfm (accessed on 16 November 2020).

70. ONZETRA®Xsail®[Package Insert]. Currax ${ }^{\mathrm{TM}}$ Pharmaceuticals LLC, 2019. Available online: https://www.onzetra.com/sites/ default/files/onzetra_xsail_prescribing_information.pdf (accessed on 10 November 2020).

71. Tepper, S.J.; Cady, R.K.; Silberstein, S.; Messina, J.; Mahmoud, R.A.; Djupesland, P.G.; Shin, P.; Siffert, J. AVP-825 breath-powered intranasal delivery system containing $22 \mathrm{mg}$ sumatriptan powder vs $100 \mathrm{mg}$ oral sumatriptan in the acute treatment of migraines (The COMPASS study): A comparative randomized clinical trial across multiple attacks. Headache 2015, 55, 621-635. [CrossRef] [PubMed]

72. Cady, R.K.; McAllister, P.J.; Spierings, E.L.; Messina, J.; Carothers, J.; Djupesland, P.G.; Mahmoud, R.A. A randomized, doubleblind, placebo-controlled study of breath powered nasal delivery of sumatriptan powder (AVP-825) in the treatment of acute migraine (The TARGET Study). Headache 2015, 55, 88-100. [CrossRef] [PubMed]

73. Silberstein, S.; Winner, P.K.; McAllister, P.J.; Tepper, S.J.; Halker, R.; Mahmoud, R.A.; Siffert, J. Early Onset of Efficacy and Consistency of Response Across Multiple Migraine Attacks from the Randomized COMPASS Study: AVP-825 Breath Powered ${ }^{\circledR}$ Exhalation Delivery System (Sumatriptan Nasal Powder) vs Oral Sumatriptan. Headache 2017, 57, 862-876. [CrossRef]

74. TOSYMRA ${ }^{\mathrm{TM}}$ Nasal Spray [Package Insert]. Upsher-Smith Laboratories, LLC, 2019. Available online: http:/ /www.upsher-smith. com/wp-content/uploads/TOS-MI.pdf (accessed on 31 March 2021).

75. Dr. Reddy's Laboratories and Its U.S. Subsidiary, Promius Pharma, Announce FDA Approval for TOSYMRA ${ }^{\mathrm{TM}}$ (Sumatriptan Nasal Spray) 10 mg, in the U.S. Market. Available online: https:/ / www.biospace.com/article/releases/dr-reddy-s-laboratories-and-itsu-s-subsidiary-promius-pharma-announce-fda-approval-for-tosymra-sumatriptan-nasal-spray-10-mg-in-the-u-s-market/ (accessed on 16 November 2020).

76. Munjal, S.; Gautam, A.; Offman, E.; Brand-Schieber, E.; Allenby, K.; Fisher, D.M. A Randomized Trial Comparing the Pharmacokinetics, Safety, and Tolerability of DFN-02, an Intranasal Sumatriptan Spray Containing a Permeation Enhancer, With Intranasal and Subcutaneous Sumatriptan in Healthy Adults. Headache 2016, 56, 1455-1465. [CrossRef]

77. Munjal, S.; Brand-Schieber, E.; Allenby, K.; Spierings, E.L.H.; Cady, R.K.; Rapoport, A.M. A multicenter, open-label, long-term safety and tolerability study of DFN-02, an intranasal spray of sumatriptan $10 \mathrm{mg}$ plus permeation enhancer DDM, for the acute treatment of episodic migraine. J. Headache Pain 2017, 18, 31. [CrossRef] [PubMed]

78. Lipton, R.B.; Munjal, S.; Brand-Schieber, E.; Rapoport, A.M. DFN-02 (Sumatriptan 10 mg With a Permeation Enhancer) Nasal Spray vs Placebo in the Acute Treatment of Migraine: A Double-Blind, Placebo-Controlled Study. Headache 2018, 58, 676-687. [CrossRef] [PubMed]

79. Duquesnoy, C.; Mamet, J.P.; Sumner, D.; Fuseau, E. Comparative clinical pharmacokinetics of single doses of sumatriptan following subcutaneous, oral, rectal and intranasal administration. Eur. J. Pharm. Sci. 1998, 6, 99-104. [CrossRef]

80. IMITREX Product Monograph. Available online: https://ca.gsk.com/media/527922/imitrex.pdf (accessed on 24 February 2021).

81. MIGRANAL Product Monograph. Available online: http://sterimaxinc.com/wp-content/uploads/2016/03/1.3.1-MigranalSteriMax-English-PM-February-9-2016.pdf (accessed on 24 February 2021). 
82. Yates, R.; Sorensen, J.; Bergstrom, M.; Antoni, G.; Nairn, K.; Kemp, J.; Langstrom, B.; Dane, A. Distribution of intranasal C-zolmitriptan assessed by positron emission tomography. Cephalalgia 2005, 25, 1103-1109. [CrossRef]

83. Seaber, E.; On, N.; Dixon, R.M.; Gibbens, M.; Leavens, W.J.; Liptrot, J.; Chittick, G.; Posner, J.; Rolan, P.E.; Pack, R.W. The absolute bioavailability and metabolic disposition of the novel antimigraine compound zolmitriptan (311C90). Br. J. Clin. Pharmacol. 1997, 43, 579-587. [CrossRef]

84. Dowson, A.J.; Charlesworth, B.R.; Purdy, A.; Becker, W.J.; Boes-Hansen, S.; Farkkila, M. Tolerability and consistency of effect of zolmitriptan nasal spray in a long-term migraine treatment trial. CNS Drugs 2003, 17, 839-851. [CrossRef]

85. Obaidi, M.; Offman, E.; Messina, J.; Carothers, J.; Djupesland, P.G.; Mahmoud, R.A. Improved pharmacokinetics of sumatriptan with Breath Powered ${ }^{\mathrm{TM}}$ nasal delivery of sumatriptan powder. Headache 2013, 53, 1323-1333. [CrossRef]

86. McGinley, J.S.; Buse, D.C.; Shulman, K.J.; Wirth, R.J.; Hugentobler, E.; Lipton, R.B. Evaluating Mean Level and Within-Person Consistency in Migraine Pain Intensity and Migraine-Related Disability for AVP-825 vs Oral Sumatriptan: Results from the COMPASS Study, A Randomized Trial. Headache 2019, 59, 1002-1013. [CrossRef]

87. Maggio, E.T. Intravail: Highly effective intranasal delivery of peptide and protein drugs. Expert Opin. Drug Deliv. 2006, 3, 529-539. [CrossRef]

88. Pillion, D.J.; Hosmer, S.; Meezan, E. Dodecylmaltoside-mediated nasal and ocular absorption of lyspro-insulin: Independence of surfactant action from multimer dissociation. Pharm. Res. 1998, 15, 1637-1639. [CrossRef]

89. Albrecht, D.; Iwashima, M.; Dillon, D.; Harris, S.; Levy, J. A Phase 1, Randomized, Open-Label, Safety, Tolerability, and Comparative Bioavailability Study of Intranasal Dihydroergotamine Powder (STS101), Intramuscular Dihydroergotamine Mesylate, and Intranasal DHE Mesylate Spray in Healthy Adult Subjects. Headache 2020, 60, 701-712. [CrossRef]

90. Satsuma Pharmaceuticals Announces Topline Results from EMERGE Phase 3 Trial of STS101 for the Acute Treatment of Migraine. Available online: https://www.globenewswire.com/news-release/2020/09/10/2091685/0/en/Satsuma-PharmaceuticalsAnnounces-Topline-Results-from-EMERGE-Phase-3-Trial-of-STS101-for-the-Acute-Treatment-of-Migraine.html (accessed on 13 November 2020).

91. Aurora, S.; Jeleva, M.; Hocevar-Trnka, J.; Hoekman, J.; Shrewsbury, S. A Long-Term, Open-label Study of Safety and Tolerability of Precision Olfactory Delivery of DHE in Acute Migraine (STOP 301): Clinical Results. In Proceedings of the Migraine Trust Virtual Symposium (Online), 3-9 October 2020; Available online: https:/ /virtual.mtis2020.org/ (accessed on 2 June 2021).

92. Lipton, R.B.; Munjal, S.; Buse, D.C.; Alam, A.; Fanning, K.M.; Reed, M.L.; Schwedt, T.J.; Dodick, D.W. Unmet Acute Treatment Needs From the 2017 Migraine in America Symptoms and Treatment Study. Headache 2019, 59, 1310-1323. [CrossRef] [PubMed]

93. Shrewsbury, S.B.; Ray, S. Impact and Burden of Episodic, Acute Migraine (I-BEAM): A Patient Experience Study. In Proceedings of the 19th Congress of the International Headache Society, Dublin, Ireland, 5-8 September 2019. IHC-PO-299.

94. Gallagher, R.M.; Kunkel, R. Migraine Medication Attributes Important for Patient Compliance: Concerns about Side Effects May Delay Treatment. Headache J. Head Face Pain 2003, 43, 36-43. [CrossRef] [PubMed]

95. Lipton, R.B.; Stewart, W.F. Acute Migraine Therapy: Do Doctors Understand What Patients With Migraine Want From Therapy? Headache J. Head Face Pain 1999, 39. [CrossRef]

96. Shrewsbury, S.B.; Aurora, S.; Hoekman, J.; Jeleva, M. Patient Acceptability of a Novel Upper Nasal Delivery System for DHEUsing the Precision Olfactory Delivery (POD) Device (INP104). In Proceedings of the Migraine Trust Virtual Symposium 2020 (Online), 3-9 October 2020, MTV20-DP-032. 